\title{
Thyroid function and autoimmunity in Danish pregnant women after an iodine fortification program and associations with obstetric outcomes
}

\author{
Sofie Bliddal ${ }^{1}$, Malene Boas ${ }^{2}$, Linda Hilsted ${ }^{3}$, Lennart Friis-Hansen ${ }^{4}$, Ann Tabor ${ }^{5}$ \\ and Ulla Feldt-Rasmussen ${ }^{1}$ \\ Departments of ${ }^{1}$ Medical Endocrinology, Section 2132, ${ }^{2}$ Growth and Reproduction and ${ }^{3}$ Clinical Biochemistry, \\ Copenhagen University Hospital (Rigshopitalet), Blegdamsvej 9, 2100 Copenhagen, Denmark, ${ }^{4}$ Department of \\ Clinical Biochemistry, Slagelse-Naestved Hospital, Naestved, Denmark and ${ }^{5}$ Department of Obstetrics, \\ Center of Fetal Medicine, Copenhagen University Hospital (Rigshospitalet), Copenhagen, Denmark
}

\author{
Correspondence \\ should be addressed \\ to S Bliddal \\ Email \\ sofiebliddal@gmail.com
}

\section{Abstract}

Objective: Aberrations in maternal thyroid function and autoimmunity during pregnancy have been associated with negative obstetric outcome. In Denmark, a national iodine fortification program was implemented in the year 2000 with the aim to alleviate the mild-moderate iodine deficiency. Following the iodine implementation, there has been an increase in thyroid autoimmunity in the background population. This study investigates the thyroid status of pregnant Danish women following the iodine fortification program, and a possible association with preterm delivery.

Design: Historical cohort study of 1278 randomly selected pregnant Danish women attending the national Down's syndrome screening program.

Methods: The main outcome measures were thyroid status according to laboratory- and gestational-age-specific reference intervals, and association with risk of abnormal obstetric outcome. Antibody-positivity was defined as an antibody-level (thyroid peroxidase and/or thyroglobulin antibodies) above $60 \mathrm{U} / \mathrm{ml}$.

Results: Establishing laboratory-specific gestational-age-dependent reference intervals, we found a prevalence of maternal thyroid dysfunction of $10 \%-15.8 \%$ by use of the cut-off suggested by the American Thyroid Association. Thyroid dysfunction was significantly associated with antibody-positivity $(P<0.05)$. No associations were found between preterm delivery and thyroid dysfunction (adjusted OR $0.6,95 \% \mathrm{Cl}: 0.1-2.3$ ) or autoimmunity (adjusted OR 1.1, 95\% Cl: 0.4-2.7). Conclusions: After the implementation of the Danish iodine fortification program, the prevalence of thyroid dysfunction and autoimmunity in Danish pregnant women is high - even higher by use of pre-established reference intervals from international consensus guidelines. However, no associations were found with abnormal obstetric outcome. Large randomized controlled trials are needed to clarify the benefit of treating slight aberrations in pregnant women's thyroid function.

\section{Introduction}

Fetal development and obstetric outcome depend on normal maternal thyroid function $(1,2,3,4)$. Fetal capacity of thyroid hormone production and secretion begins at 14-16 weeks of gestation whereas fetal consumption of thyroid hormone begins as early as $8-10$ weeks of gestation (5). Therefore, throughout the first trimester the fetus depends solely on maternal thyroid hormones crossing the placenta, and even at birth the 
maternal contribution to fetal serum thyroxine $\left(\mathrm{T}_{4}\right)$ is high $(5,6)$.

Physiological changes to maternal thyroid status occur during pregnancy (4). The pregnancy hormone human chorionic gonadotropin stimulates the thyrotropin (TSH)-receptor, which leads to a rise in circulating thyroid hormones and, by negative feedback, a decrease in TSH-levels. Other factors affect maternal thyroid function (estrogen-induced increase in $\mathrm{T}_{4}$-binding globulins, increased renal iodine clearance, placental deiodination of thyroid hormones, etc.). These changes in maternal thyroid hormone economy necessitate the establishment of gestational-age-dependent and method-specific reference intervals to secure proper diagnosis and treatment of thyroid disorders in pregnancy $(7,8)$.

In the year 2000, Denmark implemented a national iodine fortification program, which has improved the iodine status of the country from moderately iodine deficient to sufficient (9). Boas et al. (10) have previously published longitudinal reference intervals from 132 pregnant women from Copenhagen attending prenatal care in 1999-2001. However, following the national iodine fortification program, thyroid function reference intervals based on a large number of Danish pregnant women are still to be described. Upon the iodine fortification program, Pedersen et al. (11) showed that the prevalence of thyroid peroxidase antibodies (TPOAbs) and thyroglobulin antibodies (TgAbs) increased in the background population, especially in young women. None of the data pertained to pregnant women. As previous studies have suggested an association between maternal thyroid autoantibodies and abnormal obstetric outcome $(2,3)$, a study of Danish pregnant women could provide valuable information to further clarify the risks of thyroid dysfunction during pregnancy.

The aim of the present study was to examine the thyroid status of Danish pregnant women from the Copenhagen area in the first part of their pregnancy, focusing especially on the prevalence of thyroid hypofunction and thyroid autoantibodies. Furthermore, we wanted to investigate a possible association between maternal thyroid status and obstetric outcome.

\section{Subjects and methods}

This study was a historical cohort study of Danish pregnant women who participated in the national hospitalized first trimester risk assessment for Down's syndrome using the double test (pregnancy-associated plasma protein $A$ and free human chorionic gonadotropin- $\beta$ chain (hCG- $\beta$ )) and the nuchal translucency scan. Among all women attending the Down's syndrome screening at the Copenhagen University Hospital (Rigshospitalet) in 2008, 1278 women $(23.8 \%)$ were randomly selected by analyzing the first $\sim 105$ identity-encrypted blood samples stored in each calendar month. Women with twin pregnancies and/or known thyroid disease or diabetes were excluded from all analyses (Fig. 1).

The study was approved by the Scientific Ethical Committee of Region $\mathrm{H}$ (subdivision of the Danish National Ethics Committee) (project H-1-2010-014) and the Danish Data Protection Agency (file number 201241-0876). For this historical study, the Scientific Ethical Committee of Region $\mathrm{H}$ did not find the need to obtain written informed consent from the included women.

\section{Laboratory methods}

The samples had been drawn between midmorning and afternoon and subsequently stored as sera at $-80^{\circ} \mathrm{C}$. All blood samples were analyzed at the Department of

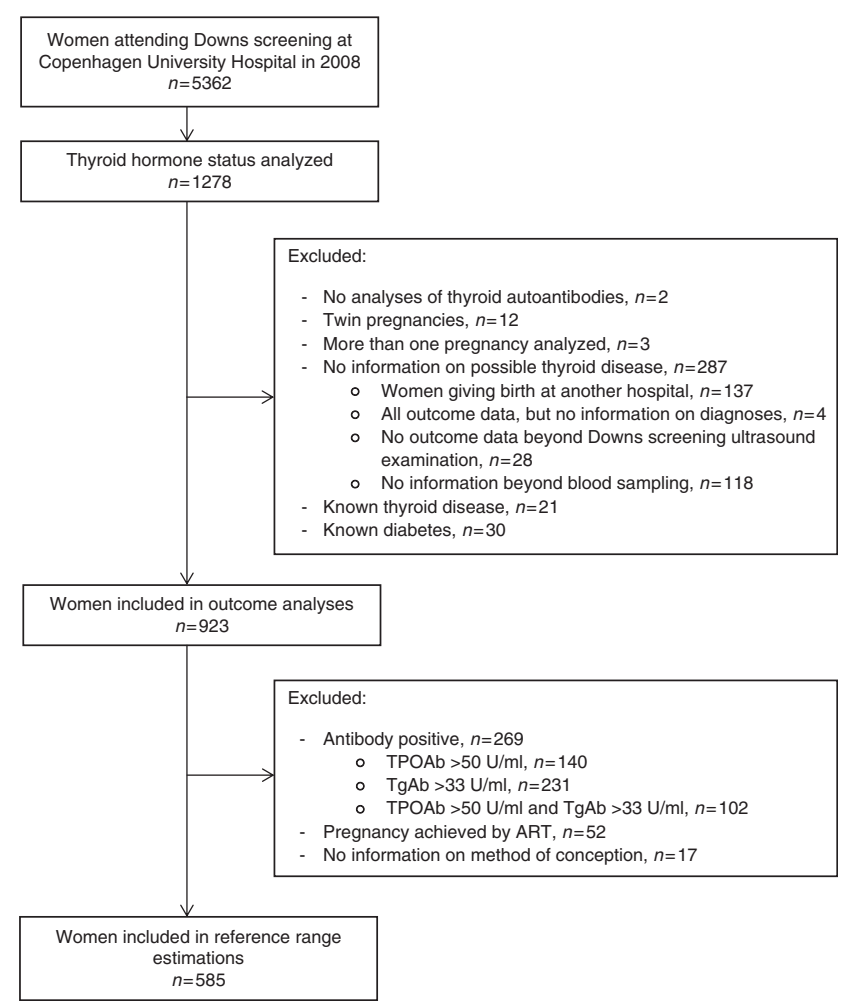

Figure 1

Flowchart of inclusion process. ART, assisted reproductive technology; TgAbs, thyroglobulin antibodies; TPOAbs, thyroid peroxidase antibodies. 
Clinical Biochemistry, Copenhagen University Hospital (Rigshospitalet). Upon thawing, electrochemiluminescence immunoassays on the Roche Modular E170 platform (Roche Diagnostics $\mathrm{GmbH}$ ) was used to analyze the following: TSH, total $\mathrm{T}_{4}\left(\mathrm{TT}_{4}\right)$, free $\mathrm{T}_{4}\left(\mathrm{FT}_{4}\right)$, total tri-iodothyronine $\left(\mathrm{TT}_{3}\right)$, free $\mathrm{T}_{3}\left(\mathrm{FT}_{3}\right)$. The corresponding inter-assay coefficients of variance $(\mathrm{CV})$ were: $7.2,3.2$ and $3.3 \%$ at concentrations of $0.04,0.2$ and $3.7 \mathrm{mU} / \mathrm{l}$ respectively for TSH; 2.7, 2.6 and $3.6 \%$ at concentrations of $14.9,17.5$ and $35.9 \mathrm{pmol} / 1$ respectively for $\mathrm{FT}_{4} ; 5.1,2.5$ and $3.7 \%$ at concentrations of 2.8, 5.9 and $15.5 \mathrm{pmol} / \mathrm{l}$ respectively for $\mathrm{FT}_{3}, 3.7,3.4$ and $4.2 \%$ at concentrations of $65.9,79.1$ and $231 \mathrm{nmol} / 1$ respectively for $\mathrm{TT}_{4} ; 4.5,3.4$ and $3.7 \%$ at concentrations of $1.2,2.3$ and $7.1 \mathrm{nmol} / 1$ respectively for $\mathrm{TT}_{3}$.

TPOAbs (functional assay sensitivity $<50 \mathrm{U} / \mathrm{ml}$ ), TgAbs (functional assay sensitivity $33 \mathrm{U} / \mathrm{ml}$ ), hcg- $\beta$ and thyroglobulin, were analyzed by immunofluorescence assays on the Kryptor instrument (B.R.A.H.M.S., Thermo Scientific, Hennigsdorf, Germany).

\section{Obstetric outcome data}

As part of the first trimester risk assessment, a nuchal translucency scan was performed at the Center of Fetal Medicine. Data from this examination provided the biometric measurements, i.e., crown-rump-length, to establish the gestational age of the fetuses. Data regarding background variables and outcome of pregnancy were collected from obstetric databases accessible at the Department of Obstetrics. These databases contained information regarding maternal height, pre-pregnancy BMI, parity, smoking habits, method of conception, gestational age at birth, birth weight, birth length, Apgar score, placental weight, birth outcome (stillbirth/live birth), birth method (planned caesarean section/acute caesarean section/spontaneous delivery, etc.) and confirmed maternal diagnoses, i.e., known thyroid disease and diabetes.

\section{Statistical analysis}

Estimation of the sample size was based upon an assumed $5 \%$ prevalence thyroid hypofunction in women of childbearing age in the Copenhagen area (12). We wanted to assess this prevalence with a $0.05 \alpha$-level, a power of 0.80 and a width of the $\mathrm{CI}$ around the proportion of 0.025 . The power calculation derived a sample size of minimum 1168 (13). All data collected in this study were analyzed using SPSS Statistics, version 20.0 (IBM).

The primary outcome of the study was gestational age at birth with preterm delivery defined as delivery before
37 weeks of gestation. Preterm delivery was further stratified into the following groups: extremely preterm ( $<28$ weeks of gestation), very preterm ( $\geq 28$ to $<33$ weeks of gestation) and preterm ( $\geq 33$ to $<37$ weeks of gestation).

Thyroid hormone variables were log-transformed to approach normal distribution. The reference intervals were calculated in Microsoft Excel 2007 as the mean \pm two s.D. of the log-transformed thyroid hormone values and then inversely transformed to yield the actual reference intervals. Furthermore, for comparison, reference intervals were also established based upon the 2.5 and 97.5 percentiles. In the calculations of reference intervals, in addition to the women with twin pregnancies and/or known thyroid disease or diabetes, all women with a thyroid antibody level (either TgAb and/or TPOAb) above the functional assay sensitivity were excluded as well as women who had become pregnant by assisted reproductive technologies (Fig. 1). Binary and linear regression analyses were used to evaluate the associations between obstetric outcome and maternal antibody status as well as thyroid status (based upon the calculated reference intervals). The data material was controlled for the following possible confounders: gestational age at time of blood sampling, maternal age at time of blood sampling, pre-pregnancy $\mathrm{BMI} \times \mathrm{BMI}$, parity, smoking status and method of conception (pregnancy achieved by assisted reproductive technology). Ethnicity (Caucasian, Afrocaribian, Asian, Oriental and 'other') was included as covariate in the regression analyses regarding thyroid dysfunction. Gestational age at birth was included as covariate in the regression analyses regarding birth weight, birth length, placental weight and Apgar score.

\section{Results}

In total, blood samples were analyzed from 1278 women. Figure 1 illustrates the subsequent exclusion process. More than one blood sample had been analyzed in three cases. For these women, outcome data existed for the second pregnancy, which we chose to include (no difference in antibody status occurred between these three women's first and second blood sample). Of the 975 women with information on diagnosed diseases, 21 women (2.2\%) with known thyroid disease and 32 women (3.3\%) with gestational diabetes (two of whom had known thyroid disease) were excluded. In total, 923 women were included in the obstetric outcome analyses and 585 women in the reference interval calculations (Fig. 1). Demographics for the women are shown in Table 1. 
Table 1 Demographics according to antibody-positivity.

\begin{tabular}{l} 
Demographics \\
\hline GA at blood sampling (weeks), \\
mean (s.D.) \\
Maternal age (years), mean (s.D.) \\
Pre-pregnancy BMI (kg/m²), \\
mean (s.D.) \\
Smoking at screening, $n(\%)$ \\
Pregnancy achieved by ART, $n(\%)$ \\
Primipara, $n(\%)$ \\
Primigravida, $n(\%)$ \\
P $(\%)$
\end{tabular}

\begin{tabular}{ccc}
\hline & & $\mathbf{A b}$ \\
\cline { 1 - 1 } $11.3(1.3)$ & & $11.2(1.3)$ \\
& & \\
$32.6(4.3)^{a}$ & & $32.4(4.4)^{a}$ \\
$22.7(4.2)$ & & $22.6(3.4)$ \\
& & \\
$6(5.8)$ & & $3(3.8)$ \\
$11(10.9)$ & & $6(7.7)$ \\
$50(47.2)^{a}$ & & $37(46.3)^{a}$ \\
$28(26.4)^{a}$ & $21(26.3)^{a}$ \\
\hline
\end{tabular}

$\mathbf{A b}+\mathbf{v e}$

$\mathrm{Ab}+\mathrm{ve}$, antibody-positive; $\mathrm{Ab}-\mathrm{ve}$, antibody-negative; ART, assisted reproductive technologies; GA, gestational age; TPO, thyroperoxidase; Tg, thyroglobulin. * $P=0.08$.

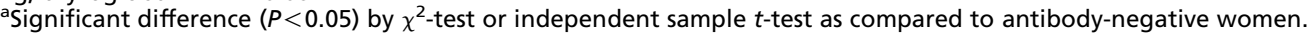

\section{Defining thyroid dysfunction}

In women included in reference interval calculations, blood samples were drawn between 6 and 20 weeks of gestation (mean 11.2 (s.D. 1.15)). Thyroid dysfunction was classified based on trimester-specific reference intervals (Table 2). Thyroid dysfunction was found in $10.0 \%$ of all included women - subclinical hypothyroidism (3.0\%) being the most prevalent (Table 3 ). These numbers were found by use of the established laboratory-specific and gestational-age-dependent reference intervals based on percentiles. Figure 2 illustrate different reference intervals (upper figure) and the proportion of women in the present cohort with a TSH outside of each of these (lower figure). If applying the trimester-specific reference intervals suggested by the American Thyroid Association guidelines (14) (and Endocrine Society (15)), 17.5\% of women in the first trimester had a TSH-concentration above or below guidelines (Fig. 2, lower figure).

\section{Thyroid autoimmunity}

Antibody-positivity was found in $16.1 \%$ of the women, but only $5 \%$ had both TPOAbs and TgAbs (Table 3 ). Antibody-positive women were significantly $(P<0.05)$ older and had had more previous pregnancies and births than antibody-negative women (Table 1). However, when entering these three covariates in a binary logistic regression model, only maternal age remained consistently significant, while parity lost all significant association with antibody-positivity.

Regardless of the cut-off used, there was a significant association $(P<0.05)$ between antibody-positivity and thyroid dysfunction. Using our clinical cut-off for antibody positivity of $60 \mathrm{U} / \mathrm{ml}, 8.6 \%$ of antibody-negative women had thyroid dysfunction, while the corresponding number in women who were either TgAb- or TPOAbpositive was $14.0 \%$ (Table 3$)(\mathrm{OR}=2.2$, 95\% CI: $1.3-3.8$, $P<0.01)$. The risk of thyroid dysfunction was the highest (24.4\%) amongst women who were both TgAb- and TPOAb-positive as compared to antibody-negative $(\mathrm{aOR}=3.6,95 \% \mathrm{CI}: 1.7-7.6, P=0.001)$. Only 19 women (2.1\%) had both TPOAb-levels above $60 \mathrm{mU} / 1$ and thyroid dysfunction. None of the antibody-positive women were overtly hyperthyroid or hyperthyroxinemic.

Table 2 Reference intervals from antibody-negative pregnant Danish women in the first and second trimester.

\begin{tabular}{|c|c|c|c|c|}
\hline \multirow[b]{3}{*}{ Analyte } & \multicolumn{4}{|c|}{ Reference intervals } \\
\hline & \multicolumn{2}{|c|}{ Calculated $^{\mathrm{a}}$} & \multicolumn{2}{|c|}{ Percentiles } \\
\hline & $\begin{array}{l}\text { Lower } \\
\text { limit }\end{array}$ & $\begin{array}{l}\text { Upper } \\
\text { limit }\end{array}$ & $2.5 \%$ & $97.5 \%$ \\
\hline \multicolumn{5}{|c|}{ First trimester (mean GA in weeks 10.8 (S.D. 0.9)) } \\
\hline $\mathrm{TSH}(\mu \mathrm{U} / \mathrm{ml})(n=455)$ & 0.2 & 6.8 & 0.1 & 3.6 \\
\hline Total $\mathrm{T}_{4}(\mathrm{nmol} / \mathrm{l})(n=454)$ & 84.6 & 165.2 & 85.3 & 166.9 \\
\hline Free $\mathrm{T}_{4}(\mathrm{pmol} / \mathrm{l})(n=454)$ & 11.4 & 18.8 & 11.7 & 19.1 \\
\hline Total $\mathrm{T}_{3}(\mathrm{nmol} / \mathrm{l})(n=455)$ & 1.4 & 2.9 & 1.4 & 3.4 \\
\hline Free $\mathrm{T}_{3}(\mathrm{pmol} / \mathrm{l})(n=454)$ & 3.5 & 5.5 & 3.4 & 5.6 \\
\hline \multicolumn{5}{|c|}{ Second trimester (mean GA in weeks 12.7 (s.D. 0.8)) } \\
\hline $\mathrm{TSH}(\mu \mathrm{U} / \mathrm{ml})(n=126)$ & 0.4 & 5.0 & 0.3 & 3.7 \\
\hline Total $\mathrm{T}_{4}(\mathrm{nmol} / \mathrm{l})(n=124)$ & 91.9 & 161.1 & 84.9 & 154.8 \\
\hline Free $\mathrm{T}_{4}(\mathrm{pmol} / \mathrm{l})(n=124)$ & 11.1 & 17.2 & 11.0 & 16.9 \\
\hline Total $\mathrm{T}_{3}(\mathrm{nmol} / \mathrm{l})(n=126)$ & 1.5 & 3.1 & 1.5 & 3.1 \\
\hline Free $\mathrm{T}_{3}(\mathrm{pmol} / \mathrm{l})(n=125)$ & 3.3 & 5.4 & 3.3 & 5.3 \\
\hline
\end{tabular}

$\mathrm{GA}$, gestational age.

aBased upon the mean \pm two s.D. of the log-transformed values, which were then inversely transformed. 
Table 3 Thyroid dysfunction according to antibody status in healthy Danish pregnant women in the first trimester.

\begin{tabular}{|c|c|c|c|c|c|c|}
\hline \multirow[b]{2}{*}{ Thyroid status } & \multicolumn{4}{|c|}{$\mathbf{A b}+\mathbf{v e}$} & \multirow[b]{2}{*}{$\mathbf{A b}-\mathbf{v e}$} & \multirow[b]{2}{*}{ Total } \\
\hline & $\mathrm{TPO}>60$ & $\operatorname{Tg}>60$ & Both $\mathrm{Tg}$ and TPO & Either Tg and/or TPO & & \\
\hline $\begin{array}{l}\text { Euthyroid, } \\
\qquad n \text { (\% of antibody-positive) }\end{array}$ & $89(82.4)$ & $65(79.3)$ & $34(75.6)$ & $120(82.8)$ & $691(91.4)$ & $811(90.0)$ \\
\hline Thyroid dysfunction, $n(\%)$ & $19(17.6)^{a}$ & $17(21.7)^{a}$ & $11(24.4)^{a}$ & $25(17.2)^{a}$ & $65(8.6)$ & $90(10.0)$ \\
\hline Subclinical hypothyroidism & $10(9.3)$ & $9(11.0)$ & $5(11.1)$ & $14(9.7)$ & $13(1.7)$ & $27(3.0)$ \\
\hline Overt hypothyroidism & $3(2.8)$ & $4(4.9)$ & $3(6.7)$ & $4(2.8)$ & $1(0.1)$ & $5(0.6)$ \\
\hline Hypothyroxinaemia & $4(3.7)$ & $3(3.7)$ & $2(4.4)$ & $5(3.4)$ & $17(2.2)$ & $22(2.4)$ \\
\hline Hyperthyroxinaemia & $0(0)$ & $0(0)$ & $0(0)$ & $0(0)$ & $13(1.7)$ & $13(1.4)$ \\
\hline Subclinical hyperthyroidism & $2(1.9)$ & $1(1.2)$ & $1(2.2)$ & $2(1.4)$ & $13(1.7)$ & $15(1.7)$ \\
\hline Overt hyperthyroidism & $0(0)$ & $0(0)$ & $0(0)$ & $0(0)$ & $8(1.1)$ & $8(0.9)$ \\
\hline Total, $n$ ( $\%$ of total) & $108(12.0)$ & $82(9.1)$ & $45(5.0)$ & $145(16.1)$ & $756(83.9)$ & $901(100)$ \\
\hline
\end{tabular}

$\mathrm{Ab}+\mathrm{ve}$, antibody-positive; $\mathrm{Ab}$ - ve, antibody-negative; TPO, thyroperoxidase; Tg, thyroglobulin.

${ }^{a}$ Significantly $(P<0.05)$ higher proportion of women with thyroid dysfunction as compared to antibody-negative group by both $\chi^{2}$-test and adjusted logistic regression (covariates: gestational week at time of blood sampling, maternal visit age, pre-pregnancy BMI $\times$ BMI, smoking status, ethnicity and parity).

\section{Missing data}

Women $(n=287)$ with complete blood analysis, but no information on possible pre-existing thyroid disease were excluded from reference interval calculations and all outcome analyses. Of these, 146 (11.4\%) had no records on outcome data (i.e., ultrasound examination and/or birth outcome). Neither antibody-positivity (TPOAb and/or TgAb) nor thyroid hormone status differed significantly ( $P=0.60$ and $P=0.36$ respectively) between the women with missing data and the women included in outcome analyses.

\section{Obstetric outcome}

One child was stillborn at term (37.9 weeks of gestation). The obstetric records stated that this was a high-risk pregnancy with a maternal disease (no record of which) complicating the pregnancy, resulting in intrauterine growth restriction and fetal death. The woman was antibody-negative (TPOAb $28 \mathrm{U} / \mathrm{ml}$ ) and had thyroid hormone levels within the cohort reference interval (TSH $0.4 \mu \mathrm{U} / \mathrm{ml}, \mathrm{FT}_{4} 12.3 \mathrm{pmol} / \mathrm{l}, \mathrm{TT}_{4} 122.5 \mathrm{nmol} / \mathrm{l}, \mathrm{FT}_{3}$ $4.1 \mathrm{pmol} / 1$ and $\left.\mathrm{TT}_{3} 2.2 \mathrm{nmol} / \mathrm{l}\right)$.

Preterm birth occurred in 38 (4.1\%) of the included pregnancies (Table 4). No children were born extremely preterm. Of the ten children born very preterm, none of the mothers had TPOAbs, TgAbs, or thyroid dysfunction. In the remaining 28 pregnancies resulting in birth between gestational weeks 33 and 37, six women were antibody-positive (one TPOAb-positive, three TgAbpositive and two both); all were euthyroid at the time of blood sampling. Two antibody-negative women with thyroid levels outside of the reference interval gave birth preterm; one with overt hyperthyroidism (TSH $0.02 \mathrm{mU} / \mathrm{l}$, $\mathrm{FT}_{4} 22.5 \mathrm{pmol} / 1, \mathrm{TT}_{4} 178.2 \mathrm{nmol} / 1, \mathrm{FT}_{3} 5.8 \mathrm{nmol} / 1$ and $\mathrm{TT}_{3}$ $2.8 \mathrm{nmol} / \mathrm{l}$ ), the other with high $\mathrm{FT}_{4}$-levels (TSH $1.1 \mathrm{mU} / 1$, $\mathrm{FT}_{4} 20.4 \mathrm{pmol} / \mathrm{l}, \mathrm{TT}_{4} 144.5 \mathrm{nmol} / \mathrm{l}, \mathrm{FT}_{3} 4.5 \mathrm{nmol} / 1$ and $\mathrm{TT}_{3}$ $1.7 \mathrm{nmol} / 1)$.

Regarding perinatal outcome, no associations were found with neither antibody-positivity nor thyroid dysfunction in $\chi^{2}$-analyses or independent sample $t$-tests (Table 4). In the adjusted regression analyses, TPOAbpositivity predicted a minor increase in birth weight (99.2 g (95\% CI: 8.5-190.1), $P=0.03)$. We did not find a significant effect of any of the included covariates on preterm delivery. There was a very small but significant $(P<0.05)$ increased effect of maternal age and BMI on the risk of labor resulting in acute cesarean section (method of conception had a borderline significant effect $(P=0.07)$ ). Higher parity had a significantly protective effect on the risk of acute cesarean section $(P<0.001$, OR $0.5,95 \% \mathrm{CI}$ : 0.3-0.7). As expected, gestational age at birth had a highly significant $(P<0.001)$ effect on birth weight, birth length and placental weight. Birth weight and placental weight were also significantly affected by higher maternal parity and BMI. None of the other covariates had a significant effect when entered into the described models.

\section{Discussion}

In Danish pregnant women, slight aberrations in thyroid function and thyroid antibody-positivity were highly prevalent, but none of them predicted an increased risk of preterm delivery or other abnormal obstetrical outcome. A heterogeneous sum of previous studies have drawn both similar $(16,17,18,19)$ and opposite conclusions $(20,21)$. 

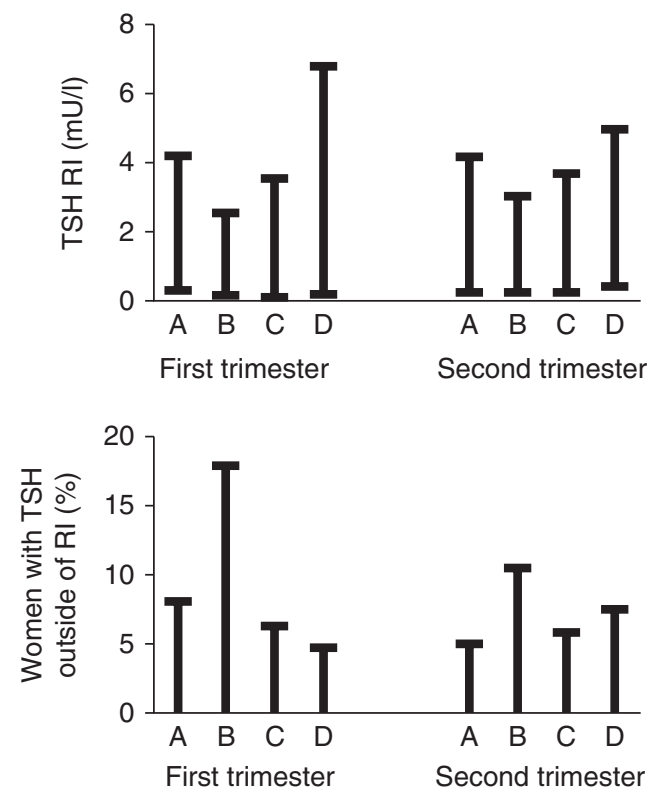

\section{Figure 2}

Variations in TSH-RIs and effect on prevalence of TSHabnormalities. TSH-RIs (upper figure) and according prevalences of TSH-abnormalities in the present cohort of pregnant women (lower figure). TSH-RIs according to: (A) the standard laboratory-specific RI (non-pregnant individuals), (B) the trimester-specific RIs suggested by the American Thyroid Association guidelines, $(C)$ the laboratory- and gestational-agespecific Rls for pregnant women in the present cohort based on the 2.5 and 97.5 percentiles, (D) the laboratory- and gestationalage-specific Rls for pregnant women in the present cohort based on calculation of a $95 \%-\mathrm{RI}$. RI, reference interval; $\mathrm{TSH}$, thyroid stimulating hormone.

\section{Predictors of obstetric outcome}

Although possibly due to a lack of power, we did not find an association between preterm delivery, and antibodypositivity or thyroid dysfunction - neither in a priori analyses nor in the adjusted regression models. Unlike previous findings (19), adjusted regression analyses showed a slightly but significantly higher birth weight in children of TPOAb-positive women. However, this was not reproduced in $t$-tests, or in regression analyses of TPOAband/or-TgAb-positivity. Given the vast amount of analyses performed in the present study, it would seem speculative to attempt to explain the causative nature of a single positive finding ( $P=0.03$ without Bonferroni-correction).

Interestingly, higher maternal age was strongly associated with antibody-positivity and several of the obstetric outcomes, underlining the importance of adjusted analyses in this field. When controlling for maternal age, we did not find an association of parity with thyroid autoimmunity, which confirms previous findings (22) speaking against microchimerism as a strong predictor of thyroid autoimmunity.

Since 2006, 90\% of all pregnant women in Denmark have participated in the Down's syndrome screening program $(23,24)$. In Denmark, the registration of outcome data in national databases is mandatory for all hospital deliveries, and thus information from these databases is both systematic and reliable. No birth outcome data (including information on known diabetes and thyroid disease) existed for $11.4 \%$ of the women who had attended the first part of the screening program, i.e., blood sampling. These women were likely to have had early miscarriages, but they did not differ from the rest of the cohort in regard to thyroid hormone status nor antibody-positivity. However, the antibody-positive women who were included in outcome-analyses were more likely to have had previous pregnancies than antibody-negative women - also when controlling for parity. Thus, our results speak neither for nor against previous studies that have found a higher frequency of miscarriages in women with thyroid autoantibodies and/or thyroid dysfunction (2).

\section{Thyroid function after the iodine fortification program}

Results of population studies have shown that the prevalence of thyroid hypofunction in women of childbearing age living in Copenhagen was $\sim 5 \%$ before the iodine fortification program. While the iodine status in the population had markedly improved after the iodine fortification program implementation, the incidence of hypothyroidism had slightly increased (9). In concurrence with previous studies of Danish women of reproductive age (11), our results showed a $10 \%$ prevalence of thyroid dysfunction in women with no previous history of thyroid disease.

While a limitation of the present study is the lack of data on urinary iodine levels, studies from the background population in the same area have shown significantly improved urinary iodine levels albeit in the low range of recommended levels (25). However, the iodine status of young women may not be sufficient to meet the increased demands during pregnancy. In pregnant women from another part of Denmark (previously moderately iodine deficient), Andersen et al. (26) recently showed that urinary iodine levels did not meet the recommended levels despite the iodine fortification program. Finally, pregnant thyroid antibody-positive women have an increased risk of development of subclinical thyroid 

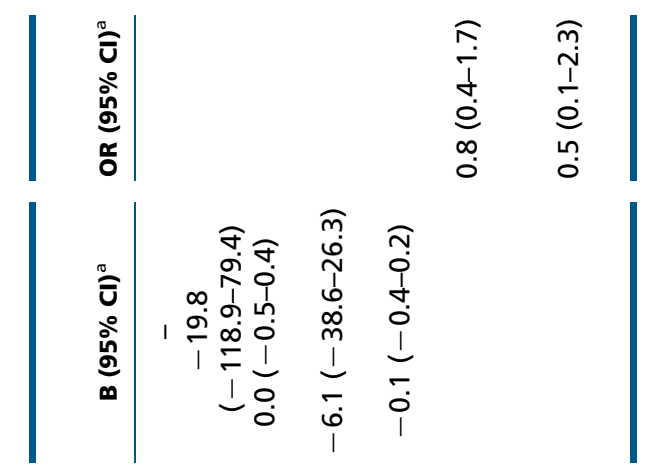

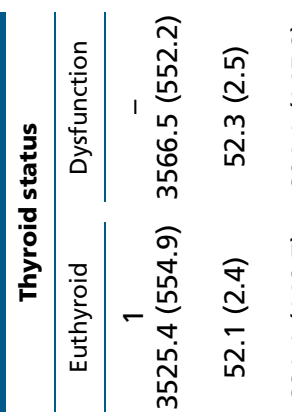

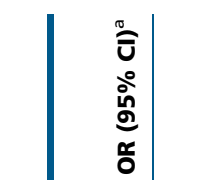

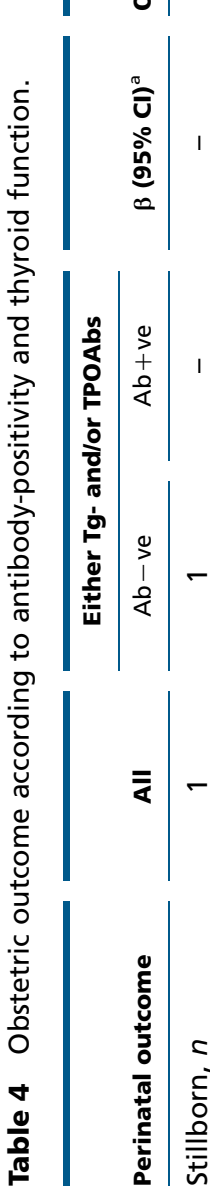

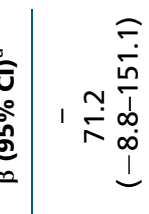

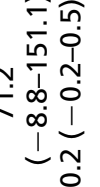

ஸั

官

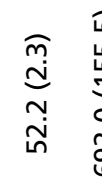

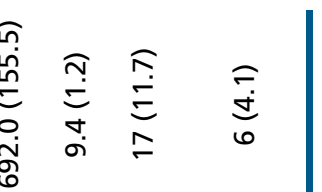

গิ

พั่

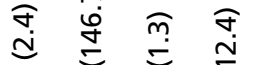

กั่

ป

$\stackrel{ }{=}$

ฮั disease (27) as pregnancy progresses, as well as of postpartum thyroid disease $(28,29)$. Therefore, our results are a cause for concern even though we did not find an association between abnormal maternal thyroid function, or antibody status, and obstetric outcome. Consideration could be given to implementing national recommendations of iodine supplementation during pregnancy (26), although a consequent increase in thyroid autoimmunity among young women is likely to occur $(11,28)$.

\section{Challenges to thyroid screening in pregnancy}

Concerns regarding the impact of abnormal maternal thyroid status on fetal development and obstetric outcome have resulted in international debate of whether to screen for maternal thyroid status antenatally - even before conception (30). In the most recent Endocrine Society Guidelines, experts within the field were not able to agree on whether to recommend universal screening or not (15). In accordance with a recent review by Laurberg et al. (31), we found a prevalence of previously undetected overt hypothyroidism of $0.6 \%$. Laurberg et al. (31) concluded that screening may be justified to detect and treat cases of overt hypothyroidism to prevent complications such as neurocognitive deficiencies in the unborn child - such an approach was found to be cost-effective in a study by Dosiou et al. (32). Although the identification of women with overt hypothyroidism is highly appealing, several caveats to implementing screening still exist. First, screening will also detect the many women (in our cohort $\sim 10 \%$ ) with abnormal thyroid function besides overt hypothyroidism, i.e., subclinical thyroid disease. For this substantial group, evidence of treatment benefits is still lacking $(33,34)$, leaving unanswered the essential question of whom to treat and how in a screening program. Second, laboratory- and gestational-age-specific reference intervals are needed in order to properly evaluate pregnant women's thyroid function. We recently found up to a $100 \%$ difference in $\mathrm{FT}_{4}$-levels when using gestational-age-specific reference intervals established in two different laboratories within the same iodine intake area of Denmark (7). In the present study, $17.5 \%$ of women in the first trimester had TSH-levels outside the reference interval suggested by the American Thyroid Association; nearly three times as many as when using our own laboratory-specific reference intervals. Similar discrepancies between suggested universal reference intervals and national reference intervals were described by Li et al. (35). This underlines the necessity of considering not only the laboratory method and the gestational week at blood sampling, but also the iodine 
status of the population, when evaluating thyroid function. Although, ideally, all populations should be iodine sufficient, this is not the case. As discussed above, population-based reference intervals of thyroid function variables are much dependent on both population, iodine intake and not least the method used for measurement (36). Gestational-age-specific reference intervals should therefore be done by the same laboratory and with the same method as the investigated subject's measurement to avoid misclassifications of thyroid status. If we had used the reference intervals suggested by the American Thyroid Association (based on the U.S. population) and had had to take action on the results, we would have had to treat nearly one in five of all (previously thyroid-healthy) pregnant women with $\mathrm{T}_{4}$ - this would hardly make sense. Instead it would be preferable to enforce extra iodine supplementation in pregnant women. Third, even well-established reference intervals do not account for the many reasons for inter- and intra-individual differences and fluctuations in TSH-levels $(10,37)$ making interpretation of possible screening results a job for specialists. Finally, the role of thyroid antibody-positivity in pregnancy is still uncertain (29). Some studies have indicated an association of thyroid autoantibodies with negative pregnancy outcomes even in euthyroid women (38). In our cohort, thyroid dysfunction was significantly more prevalent among antibody-positive women, and more than half of the women with subclinical hypothyroidism were antibody-positive. However, neither thyroid dysfunction nor antibody-positivity posed a risk to fetal outcome. Until further research has clarified the risks of thyroid dysfunction and thyroid autoimmunity in low-risk-populations and the potential benefits of treatment hereof, we suggest a cautious approach to screening. Prospective randomized controlled trials in this area are much needed.

\section{Conclusion}

Thyroid dysfunction is highly prevalent in Danish pregnant women after implementation of the national iodine fortification program. However, maternal thyroid dysfunction and/or antibody-positivity were not associated with abnormal obstetric outcomes. At present, it is possible and biochemically simple to test for and treat thyroid dysfunction, while the necessity of such extensive effort remains to be established. Evidence is still lacking from large randomized controlled trials on the risks and benefits of screening of all pregnant women and treating even slight aberrations in thyroid function. In our cohort, implementing screening programs without such evidence would cause (unnecessary?) concern in $10-18 \%$ of pregnant women without prior history of thyroid disease. Instead, a higher recommended iodine intake during pregnancy would be preferable.

The psychological consequences and the stressor of being enrolled in hospital care and medicated as a pregnant woman might very well overshadow the potential risk of slight aberrations in thyroid function and autoimmunity on preterm delivery risk. Based on our results and the lack of randomized controlled trials, we caution against the trend of pre-emptive treatment of otherwise healthy subjects.

\section{Declaration of interest}

$S$ Bliddal and $U$ Feldt-Rasmussen received an author honorarium from Merck Serono for a publication in Thyroid International.

\section{Funding}

This project and the preparation of this manuscript were supported by the following foundations to which we owe our thanks: Musikforlæggerne Agnes og Knut Mørks Foundation (2010, 2012); the Danish Council for Independent Research: Medical Sciences (2010); Axel Muusfeldt's Foundation (2010, 2013); the Foundation of 17.12.1981 (2010); Videnskabsminister Erna Hamilton Foundation (2012); Director Ib Henriksen Foundation (2012); Snedkermester Sophus Jacobsen og hustru Astrid Jacobsen's Foundation (2010, 2013); the Faculty of Medical Science's Foundation (2013); Frimodt-Heineke Foundation (2013); Torben and Alice Frimodt's Foundation (2012); A.P. Møller Foundation for the Advancement of Medical Science (2012); Familien Hede Nielsens Foundation (2013); and the Copenhagen University Foundation (2013). The research salary of U Feldt-Rasmussen was partly supported by Arvid Nilsson's Foundation. The funding sources had no influence on the design and conduct of the study, the analysis and interpretation of the study data, the drafting, revision or approval of the manuscript, or the decision to submit the manuscript for publication.

Author contribution statement

$S$ Bliddal performed the data gathering and statistical analyses and prepared the manuscript. All authors contributed to the study design, supervision of the statistical analyses and the discussion and review of the manuscript.

\section{Acknowledgements}

We are grateful for the important and enthusiastic work of midwife Lene Eskildsen in gathering the outcome data, Brian Møllgren in assisting with the laboratory analyses and Oriana Aragón (Yale University) for initial statistical guidance.

\section{References}

1 Korevaar TI, Schalekamp-Timmermans S, de Rijke YB, Visser WE, Visser W, de Muinck Keizer-Schrama SM, Hofman A, Ross HA, 
Hooijkaas $\mathrm{H}$, Tiemeier $\mathrm{H}$ et al. Hypothyroxinemia and TPO-antibody positivity are risk factors for premature delivery: the generation R study. Journal of Clinical Endocrinology and Metabolism 201398 4382-4390. (doi:10.1210/jc.2013-2855)

2 Thangaratinam S, Tan A, Knox E, Kilby MD, Franklyn J \& Coomarasamy A. Association between thyroid autoantibodies and miscarriage and preterm birth: meta-analysis of evidence. BMJ 2011342 d2616. (doi:10.1136/bmj.d2616)

3 He X, Wang P, Wang Z, He X, Xu D \& Wang B. Thyroid antibodies and risk of preterm delivery: a meta-analysis of prospective cohort studies. European Journal of Endocrinology 2012167 455-464. (doi:10.1530/ EJE-12-0379)

4 Feldt-Rasmussen U \& Mathiesen ER. Endocrine disorders in pregnancy: physiological and hormonal aspects of pregnancy. Best Practice \& Research. Clinical Endocrinology \& Metabolism 201125 875-884. (doi:10.1016/j.beem.2011.07.004)

5 Patel J, Landers K, Li H, Mortimer RH \& Richard K. Delivery of maternal thyroid hormones to the fetus. Trends in Endocrinology and Metabolism 201122 164-170. (doi:10.1016/j.tem.2011.02.002)

6 Vulsma T, Gons MH \& de Vijlder JJ. Maternal-fetal transfer of thyroxine in congenital hypothyroidism due to a total organification defect or thyroid agenesis. New England Journal of Medicine 1989321 13-16. (doi:10.1056/NEJM198907063210103)

7 Bliddal S, Feldt-Rasmussen U, Boas M, Faber J, Juul A, Larsen T \& Precht DH. Gestational age-specific reference ranges from different laboratories misclassify pregnant women's thyroid status: comparison of two longitudinal prospective cohort studies. European Journal of Endocrinology 2014170 329-339. (doi:10.1530/EJE-13-0672)

8 Lambert-Messerlian G, McClain M, Haddow JE, Palomaki GE, Canick JA, Cleary-Goldman J, Malone FD, Porter TF, Nyberg DA, Bernstein $P$ et al. First- and second-trimester thyroid hormone reference data in pregnant women: a FaSTER (First- and Second-Trimester Evaluation of Risk for aneuploidy) Research Consortium study. American Journal of Obstetrics and Gynecology 2008199 62-66. (doi:10.1016/j.ajog.2007.12.003)

9 Rasmussen LB, Carle A, Jorgensen T, Knudsen N, Laurberg P, Pedersen IB, Perrild H, Vejbjerg P \& Ovesen L. Iodine intake before and after mandatory iodization in Denmark: results from the Danish Investigation of Iodine Intake and Thyroid Diseases (DanThyr) study. British Journal of Nutrition 2008100 166-173. (doi:10.1017/ S0007114507886387)

10 Boas M, Forman JL, Juul A, Feldt-Rasmussen U, Skakkebaek NE, Hilsted L, Chellakooty M, Larsen T, Larsen JF, Petersen JH et al. Narrow intra-individual variation of maternal thyroid function in pregnancy based on a longitudinal study on 132 women. European Journal of Endocrinology 2009161 903-910. (doi:10.1530/ EJE-09-0579)

11 Pedersen IB, Knudsen N, Carlé A, Vejbjerg P, Jorgensen T, Perrild H, Ovesen L, Banke Rasmussen L \& Laurberg P. A cautious iodization program bringing iodine intake to a low recommended level is associated with an increase in the prevalence of thyroid autoantibodies in the population. Clinical Endocrinology 201175 120-126. (doi:10.1111/j.1365-2265.2011.04008.x)

12 Knudsen N, Bulow I, Jorgensen T, Laurberg P, Ovesen L \& Perrild H. Comparative study of thyroid function and types of thyroid dysfunction in two areas in Denmark with slightly different iodine status. European Journal of Endocrinology 2000143 485-491. (doi:10.1530/eje.0.1430485)

13 Eng J. Sample Size Estimation. Johns Hopkins University. 25-11-2009. http://www.rad.jhmi.edu/jeng/javarad/samplesize/oFødselsvægt/ længde.

14 Stagnaro-Green A, Abalovich M, Alexander E, Azizi F, Mestman J, Negro R, Nixon A, Pearce EN, Soldin OP, Sullivan S et al. Guidelines of the American Thyroid Association for the diagnosis and management of thyroid disease during pregnancy and postpartum. Thyroid 201121 1081-1125. (doi:10.1089/thy.2011.0087)
15 De Groot L, Abalovich M, Alexander EK, Amino N, Barbour L, Cobin RH, Eastman CJ, Lazarus JH, Luton D, Mandel SJ et al. Management of thyroid dysfunction during pregnancy and postpartum: an Endocrine Society clinical practice guideline. Journal of Clinical Endocrinology and Metabolism 201297 2543-2565. (doi:10.1210/jc.2011-2803)

16 Cleary-Goldman J, Malone FD, Lambert-Messerlian G, Sullivan L, Canick J, Porter TF, Luthy D, Gross S, Bianchi DW \& D'Alton ME. Maternal thyroid hypofunction and pregnancy outcome. Obstetrics and Gynecology 2008112 85-92. (doi:10.1097/AOG.0b013e31817 88dd7)

17 Ashoor G, Maiz N, Rotas M, Jawdat F \& Nicolaides KH. Maternal thyroid function at 11-13 weeks of gestation and spontaneous preterm delivery. Obstetrics and Gynecology 2011117 293-298. (doi:10.1097/ AOG.0b013e318205152c)

18 Haddow JE, Cleary-Goldman J, McClain MR, Palomaki GE, Neveux LM, Lambert-Messerlian G, Canick JA, Malone FD, Porter TF, Nyberg DA et al. Thyroperoxidase and thyroglobulin antibodies in early pregnancy and preterm delivery. Obstetrics and Gynecology 2010116 58-62. (doi:10.1097/AOG.0b013e3181e10b30)

19 Mannisto T, Vaarasmaki M, Pouta A, Hartikainen AL, Ruokonen A, Surcel HM, Bloigu A, Jarvelin MR \& Suvanto-Luukkonen E. Perinatal outcome of children born to mothers with thyroid dysfunction or antibodies: a prospective population-based cohort study. Journal of Clinical Endocrinology and Metabolism 200994 772-779. (doi:10.1210/ jc.2008-1520)

20 Negro R, Schwartz A, Gismondi R, Tinelli A, Mangieri T \& Stagnaro-Green A. Thyroid antibody positivity in the first trimester of pregnancy is associated with negative pregnancy outcomes. Journal of Clinical Endocrinology and Metabolism 201196 E920-E924. (doi:10.1210/ jc.2011-0026)

21 Ghafoor F, Mansoor M, Malik T, Malik MS, Khan AU, Edwards R \& Akhtar W. Role of thyroid peroxidase antibodies in the outcome of pregnancy. Journal of the College of Physicians and Surgeons-Pakistan 2006 16 468-471.

22 Pedersen IB, Laurberg P, Knudsen N, Jorgensen T, Perrild H, Ovesen L \& Rasmussen LB. Lack of association between thyroid autoantibodies and parity in a population study argues against microchimerism as a trigger of thyroid autoimmunity. European Journal of Endocrinology $2006 \mathbf{1 5 4}$ 39-45. (doi:10.1530/eje.1.02070)

23 Ekelund CK, Jorgensen FS, Petersen OB, Sundberg K \& Tabor A. Impact of a new national screening policy for Down's syndrome in Denmark: population based cohort study. BMJ 2008337 a2547. (doi:10.1136/bmj.a2547)

24 Miltoft CB, Ekelund C, Tabor A. Annual Report from the Danish Database of Fetal Medicine 2008-2010, pp 1-42, 2011.

25 Rasmussen LB, Jorgensen T, Perrild H, Knudsen N, Krejbjerg A, Laurberg P, Pedersen IB, Bjergved L \& Ovesen L. Mandatory iodine fortification of bread and salt increases iodine excretion in adults in Denmark - a 11-year follow-up study. Clinical Nutrition 201433 1033-1040. (doi:10.1016/j.clnu.2013.10.024)

26 Andersen SL, Sorensen LK, Krejbjerg A, Moller M \& Laurberg P. Iodine deficiency in Danish pregnant women. Danish Medical Journal 201360 A4657.

27 Glinoer D, Riahi M, Grun JP \& Kinthaert J. Risk of subclinical hypothyroidism in pregnant women with asymptomatic autoimmune thyroid disorders. Journal of Clinical Endocrinology and Metabolism 1994 79 197-204.

28 Nohr SB, Jorgensen A, Pedersen KM \& Laurberg P. Postpartum thyroid dysfunction in pregnant thyroid peroxidase antibody-positive women living in an area with mild to moderate iodine deficiency: is iodine supplementation safe? Journal of Clinical Endocrinology and Metabolism 200085 3191-3198. (doi:10.1210/jcem.85.9.6799)

29 Bliddal S, Feldt-Rasmussen U. TPOAbs as a risk factor in pregnancy, In Thyroid International, pp 1-20. Ed. P Smyth. Darmstadt, 2014. 
30 Lazarus JH. Screening for thyroid dysfunction in pregnancy: is it worthwhile? Journal of Thyroid Research 20112011397012. (doi:10.4061/2011/397012)

31 Laurberg P, Andersen SL, Pedersen IB, Andersen S \& Carle A. Screening for overt thyroid disease in early pregnancy may be preferable to searching for small aberrations in thyroid function tests. Clinical Endocrinology 201379 297-304. (doi:10.1111/cen.12232)

32 Dosiou C, Sanders GD, Araki SS \& Crapo LM. Screening pregnant women for autoimmune thyroid disease: a cost-effectiveness analysis. European Journal of Endocrinology 2008158 841-851. (doi:10.1530/ EJE-07-0882)

33 Lazarus JH, Bestwick JP, Channon S, Paradice R, Maina A, Rees R, Chiusano E, John R, Guaraldo V, George LM et al. Antenatal thyroid screening and childhood cognitive function. New England Journal of Medicine 2012366 493-501. (doi:10.1056/ NEJMoa1106104)

34 Vissenberg R, van den Boogaard E, van Wely M, van der Post JA, Fliers E, Bisschop PH \& Goddijn M. Treatment of thyroid disorders before conception and in early pregnancy: a systematic review. Human Reproduction Update 201218 360-373. (doi:10.1093/humupd/dms007) 35 Li C, Shan Z, Mao J, Wang W, Xie X, Zhou W, Li C, Xu B, Bi L, Meng T et al. Assessment of thyroid function during first-trimester pregnancy: what is the rational upper limit of serum TSH during the first trimester in Chinese pregnant women? Journal of Clinical Endocrinology and Metabolism 201499 73-79. (doi:10.1210/jc.2013-1674)

36 Glinoer D \& Spencer CA. Serum TSH determinations in pregnancy: how, when and why? Nature Reviews. Endocrinology 20106 526-529. (doi:10.1038/nrendo.2010.91)

37 Surks MI, Goswami G \& Daniels GH. The thyrotropin reference range should remain unchanged. Journal of Clinical Endocrinology and Metabolism 200590 5489-5496. (doi:10.1210/jc.2005-0170)

38 Toulis KA, Goulis DG, Venetis CA, Kolibianakis EM, Negro R, Tarlatzis BC \& Papadimas I. Risk of spontaneous miscarriage in euthyroid women with thyroid autoimmunity undergoing IVF: a meta-analysis. European Journal of Endocrinology 2010162 643-652. (doi:10.1530/EJE-09-0850)

Received 3 April 2015

Revised version received 19 June 2015

Accepted 6 July 2015 